\section{Machines of the Past}

The Computer from Pascal to von Neumann. By Herman H. Goldstine. Pp. $\mathrm{x}+378$. (University of Princeton: Princeton, New Jersey, January 1973.) $£ 6.25$.

IT is rare to be able to say of a new book that it is the first in its field, but such is the case with this production of Herman Goldstine. There has, up to now, been no volume devoted exclusively to the history of computers and computing, although of course many books published in the last twenty years have had a preliminary section dealing with matters historical.

Dr Goldstine has a unique title to write a history of computers because he was one of the people involved in the earliest days of the electronic era. Furthermore, as practically the last representative of the famous Princeton Institute for Advanced Studies group, Goldstine is performing a service in establishing precisely the role which the Institute played in the development of electronic computation. Goldstine himself seems to have doubts whether the Institute's role has been sufficiently recognized. From a now completely impartial position within the field, I find this one of the few statements I would dispute. Wherever electronic computation is talked about, and wherever expert groups gather, the Institute is usually credited, even now, with pioneer efforts in the field of true electronic computation.

Trained originally as a mathematician and physicist, Goldstine worked with the Moore School group on the ENIAC and its successors, transferred to the Institute for Advanced Study, where he worked with the late John von Neumann, succeeded von Neumann as Project Director, and then, with the closure of the Institute's computer project, moved to industry, which he considers the most active area now. $\mathrm{He}$ has held distinguished posts, mostly with the IBM Corporation, where he was Director of Mathematical Science at the Thomas J. Watson Research Centre, Director of Scientific Development of the Data Processing Division, and is now enjoying an honoured position as an IBM Fellow.

The book has three main parts-the first effectively historical, the second concerned with the great upsurge of computer activity in World War II, and the last dealing with activities at the Institute for Advanced Study after the conclusion of hostilities. There is also an Appendix. The opening chapter on the historical background is, perhaps, slightly skimpy, although the author has made an original contribution in his discovery of the work of Wilhelm Schickard who designed and built in 1623 a machine capable of automatic addition and subtraction and semi-automatic multiplication and division. Unfortunately, Schickard's actual device is lost, although some indications of its method of operation still exist, and the IBM Corporation, as part of its general historical and cultural activities, has made a version of the machine which is illustrated in the book. Schickarci clearly anticipated the work of Blaise Pascal who is usually credited with the invention of the first adder-subtracter in 1642. Leibniz, whose multiplier dates from about 1690 , was also anticipated, although it would seem that Schickard's methods of semi-automatic multiplication and division were quite different from the step wheel conceived by Leibniz.

As usual in books on computation, the author of this one spends some time on the English genius, Charles Babbage. Dr Goldstine appears to take a position which has been espoused by several recent writers that Babbage was a misanthrope and a crank. Here I disagree with the author, who has not, perhaps, read some of Babbage's works on the nature of industry in depth. These show that, far from being a man who continually devised new solutions to computational problems and abandoned his partially constructed devices without completion, he devoted much of his energy to the improvement of manufacturing techniques and technology in England. It is true that the technology of the time was not adequate to realize Babbage's conception, but, far from "ending it all with a bare bodkin", Babbage "took arms against a sea of troubles", and if he did not end them, he at least made some impact on the scene.

These are minor criticisms, however, for the book goes on to a fascinating discussion of the origin and provenance of the ENIAC, and includes many sidelights, generally unknown, on the wrangling and disharmony which eventually disrupted the Moore School team. The discussions about the work at the Institute for Advanced Study are, of course, seminal, and, apart from brief mentions in obituary notices of John von Neumann, have not hitherto been revealed. They are an important contribution to the history of computation. Perhaps inevitably, portions of the book, and particularly the Appendix, which deal with developments outside of the United States, are less satisfactory than the rest. For example, the attribution to Atanasoff on page 123 of the development of binary methods in digital computation completely ignores the claims of E. Williams Phillips, the English actuary whose contributions are well documented. Yet again, perhaps too much importance is attached to certain evanescent developments such as the ForresterWilliams storage tube. Perhaps more important is the omission of reference to the work of K. D. Tocher, the actual inventor of micro-programming despite the urgent protestations of some later rediscoverors. These things, however, are minor blemishes.

The book is first-rate: it is written in a style that all can understand, and where advanced mathematical techniques are mentioned, sufficient background is provided for even the lay reader to understand what is going on. Goldstine has a lucid style, and it is greatly to be hoped that in due course we shall see other productions from his pen. ANDREW D. BOOTH

\section{Observations on the Sun}

Solar Activity: Observations and Predictions. Edited by Patrick S. McIntosh and Murray Dryer. Pp. xv+444. (MIT: Cambridge, Massachusetts and London, November 1972.) $\$ 17.50$.

Wrrt this publication the MIT series on Progress in Astronautics and Aeronautics reaches its thirtieth volume. Arising out of a 1970 conference held in Huntsville, Alabama, the book com. prises twenty-five papers reviewing current knowledge of solar activity, its effects on the interplanetary and terrestrial environments, and the possibilities of predicting such phenomena. Compared with the material found in some such conference products, this work effectively avoids the pitfalls of over-specialization and subjective research opinions, a success perhaps 